\title{
Conceptual Metaphor in American Presidential Inaugural Addresses
}

\author{
Jiao Xue \\ English Ddepartment, Zhenjiang Watercraft College, Zhenjiang, China \\ Zan Mao \\ English Department, Zhenjiang Watercraft College, Zhenjiang, China \\ $\mathrm{Na} \mathrm{Li}$ \\ English Department, Zhenjiang Watercraft College, Zhenjiang, China
}

\begin{abstract}
Metaphor has long been a hot topic for linguistic scholars. Traditionally, metaphor has been viewed as a pure linguistic phenomenon and studied as a rhetoric device. Contrary to the traditional view of metaphor, American linguists Lakoff and Johnson think that metaphor is not only a form of human language, but also a matter of human action and thought. Political discourse has always been considered to be bearing strong smell of politics and influenced by ideology. Therefore, it's usually abstract and hard for people to understand. The present thesis attempts to apply conceptual metaphor theory and in American Presidential Inaugural Addresses. They like employing metaphor to express their own political thought and standpoints to persuade infect and motivate people by means of mapping concrete familiar concepts onto abstract political concepts.
\end{abstract}

Index Terms - conceptual metaphor, American presidential inaugural addresses

\section{INTRODUCTION}

Metaphor has long been a hot topic for linguistic scholars. Traditionally, metaphor has been viewed as a pure linguistic phenomenon and studied as a rhetoric device. Contrary to the traditional view of metaphor, American linguists Lakeoff and Johnson think that metaphor is not only a form of human language, but also a matter of human action and thought. Since Aristotle, there has been a vast amount of theoretical researches on metaphor from various perspectives. In recent decades, there have been some scholars studying political discourse from the perspective of metaphors.

Political discourse has always been considered to be bearing strong smell of politics and influenced by ideology. Therefore, it is usually abstract and hard for people to understand. Critical discourse analysis is mainly about the relationship between language, power and ideology. As this theory shows, language is the primary medium of practicing ideology and power, and metaphorical language is much more powerful.

This research attempts to adopt the conceptual metaphor theory to analyze political discourse. Through the analysis of the speeches of American presidents, the conceptual political metaphors in these speeches will be made clear and the basis and functions of these metaphors will be investigated. It is a systematic research of the political conceptual metaphors by analyzing typical and authentic data. This will reveal how the metaphors work in the political world. In practice, it can help people understand American politics and cultures in a certain way.

\section{THE Systematicity OF CONCEPTUAL METAPHOR}

"Metaphorical entailments can characterize a coherent system of metaphorical concepts and a corresponding coherent system of metaphorical expressions for those concepts.”(Lakeoff \& ohnson, 1980, p.9) That is to say, conceptual metaphors do not work separately, but are closely related with each other. From our own experience, we can see that not only metaphorical expressions under a conceptual metaphor can form a coherent system to express many aspects of that concept, but also different conceptual metaphors under the same concept can operate systematically.

The systematicity of metaphor is reflected in two aspects: (a) each conceptual metaphor heads and governs a system of correspondences between the source domain and target domain, for example, the systematicity of metaphorical expressions within a single conceptual metaphor; (b) conceptual metaphors may also systematically relate to each other to form a hierarchical or parallel structure.

Metaphorical systematicity has the function of highlighting and hiding. " The very systematicity that allows us to comprehend one aspect of arguing in terms of another will necessarily hide other aspects of the concept"( Lakeoff \& Johnson, 1980, p.10)

\section{Cultural Coherence of CONCePtual Metaphor}

The most fundamental values in a culture will be coherent with the metaphorical structure of the most fundamental 
concepts in the culture." (Lakoff \& Johnson1980, p.22) That is to say, the cultural values of a society are, to a large extent, expressed through metaphorical concepts. Just as Lakoff and Johnson suggest, each conceptual metaphor has what they call an "experimental" basis. In other words, Metaphors are not randomly assigned: they are rooted in our experience. Although, experience can be defined as physical experience and cultural experience, every experience still happens in a presupposed cultural background. We experience our world, in this way, our culture is already presented in the experienced itself.

\section{The Signifiance of The American Presidental InAugual AdDRESS}

The inaugural address is of great importance to the new president and his administration. In fact, it can be said that each presidential inauguration revolves around the inaugural address, which will have a lasting influence upon America. One speech writer for presidents Ford and Bush once said, The beauty of the inaugural is that we've built up a huge tradition where this is the legitimizing of the president...This is one occasion where you can go way up on the eloquence scale (Zheng, 2001). Horace Busby, who wrote the inaugural address for the 36th president Lyndon Baines Johnson, said that the day of the presidential inauguration was the first time when the newly elected president stood in front of his people as the leader of the nation instead of a candidate or a party member (Zheng, 2001).

The newly elected president often takes advantage of this chance to address the nation's divisions, publicize his fundamental political principles and policies for the next four years, and at the same time project America's place in the world. The inaugural address also sets the objective for the new government and promises a bright future to the public. The prominent aim of giving such a speech is to lay out briefly and justify the principles that will become the guide for the newly elected president in the administration of the government. More importantly, it is aimed at convincing a national audience of the appropriateness and benefits, molding public opinion, inspiring public for action, putting the new government in a favorable position and seeking the largest amount of support.

Every president knows well that it is his moment when giving the speech. At that moment, the whole nation or even the world is watching him. It is his first chance to make a good impression to the public. What he says will be regarded as a standard to measure the achievements and fulfillments of him and his government. This can also help to form his image in the country. Besides, he can use this opportunity to appeal to more people to support his government and his party, for every speaker knows that if he could manipulate or limit what is possible in language, he could manipulate or limit what is possible in thought (Wilson, 2001).

It is even argued that a president is judged as much by what he says as by what he does, and his words delivered can shape his image forever. How well a president succeeds depends on his crafting and delivery of the words to a certain extent. Many studies have pointed to the presidency as a talking institution where the American president presides through his words. It can be seen that usually the more successful presidents in American history showed stronger rhetorical abilities and presented excellent addresses such as Abraham Lincoln in 1861, Theodore Roosevelt in 1905, Franklin D.Roosevelt in 1933, John F.Kennedy in 1961, Richard Milhous Nixon in 1969 and Ronald Reagan in 1981. The first step for these presidents was a success and it could not be denied that their addresses played a role to a large extent. In contrast, such presidents as Warren G. Harding, Herbert Hoover, Gerald Ford, and Jimmy Carter whose terms in the White House have been described as less inspiring turned out to be least rhetorically gifted. This is not meant to prove that there is a certain link between the successfulness of a president in administration and his inaugural address, but for the presidents in addition to their leadership qualities, negotiation skills and administrative abilities, the rhetorical ability is also important which enable them to communicate effectively. According to Kiewe (1998), the 20th century presidency in particular has even been labeled "the rhetorical presidency" to denote a style of governing and leadership that relies heavily on public discourse and whose rhetoric equals action.

In order to achieve their goals, the new presidents often resort to language skills among other things. Among those language skills, metaphor can serve their purposes properly and effectively, therefore, many presidents adopt it widely in their inaugural addresses.

\section{PolitCAl Metaphors in American Presidental Inaugural AdDresses}

This part will identify, categorize, analyze and explain the political metaphors in the American presidential inaugural addresses. According to conceptual metaphor theory presented by George Lakoff, through a thorough examination of the metaphors identified by the five-step procedure in the addresses, the findings turn out to be very fruitful. The author has classified the major and most frequent metaphors.

\section{A. Journey Metaphors}

Lakoff (1993) defined "journey" metaphor as PURPOSEFUL ACTIVITY IS TRAVELLING ALONG A PATH TOWARD A DESTINATION. Just like a traveler. In a journey, any activities of any politicians are goal-oriented and their goals can be conceptualized as the destinations of a traveler. In American data, there are also a lot of metaphors that involve "speed", "path", "steps", "advancing", and "goals", etc. President Bush wants to employ metaphor as a tool to help him gain the support from his people about his domestic and foreign policy

For example: 
(1) We seek the end of tyranny in our world. (Bush, Jan $31^{\text {st }}, 2006$ )

(2) Far from being a hopeless dream, the advance of freedom is the great story of our time.(Bush, Jan $31^{\text {st }}, 2006$ )

(3) The only way to protect our people, the only way to secure the peace, the only way to control our destiny is by our leadership - so the united states of America will continue to lead. (Bush, Jan 20 ${ }^{\text {st }}, 2006$ )

(4) Every step toward freedom in the world makes our country safer - so we will act boldly in freedom's cause. (Bush, Jan 20" st 2006)

(5) We will choose to act confidently in pursuing the enemies of freedom or retreat from our duties in the hope of an easier life. (Bush, Jan $31^{\text {st }}, 2006$ )

Americans have strong opinion of democracy, rights and freedom. They highlight the" natural rights", and they think everyone is created equal and human rights are superior to everything. Therefore, "democratic progress" is a socially valuable activity, and we should not give up or "retreat", when confronted with difficulties. The great power of this metaphor make Americans believe that what Bush government does is to achieve democracy in the world. Thus, all the actions Bush government takes can be justified and Americans are made to support Bush's foreign policy.

For example:

(6) Tonight I will set out a better path: an agenda for a nation that competes with confidence (Bush, Jan31 $\left.{ }^{\text {st }}, 2006\right)$

(7) So tonight, I ask you to join me in creating a commission to examine the full impact of body boom retirements on social security, Medicare, and Medicaid. (Bush, Jan31 ${ }^{\text {st }}, 2006$ )

(8) To meet this goal, we must have stronger immigration enforcement and border protection. (Bush, Jan31 ${ }^{\text {st }}$, 2006)

As we can see from the above examples, Bush's domestic policy is conceptualized in terms of a journey. This metaphor forms a path that invites American people to participate in the journey.

(9) The only way to protect our people, the only way to secure the peace, the only way to control our destiny is by our leadership. (Bush, Jan31 ${ }^{\text {st }}, 2006$ )

(10) Together, let us protect our country, support the men and women who defend us, and lead this world toward freedom. (Bush, Jan31 ${ }^{\text {st }}, 2006$ )

(11) We will build the prosperity of our country by strengthening our economic leadership in the world. (Bush, Jan31 $1^{\text {st }}, 2006$ )

In the journey, if there are no maps, the traveler may get lost; therefore, he needs a guide who knows the direction for destination. In the American data, Bush mentions the word "leadership" many times, attempting to tell his citizen that America is the best and strongest nation in the world. Within this metaphor, Americans will have a sense of superiority and participate in his journey, helping him finish his so-called great cause.

\section{B. War Metaphor}

POLITICS IS WAR, this metaphor is deeply rooted in people's minds and expressed in daily language. In fact the election campaign is compared to a war. The candidates try all means to fight for the presidential position. This can be seen clearly in the news report about the presidential election.

In a war there are enemies and for the American people enemies are social drawbacks, any forces that hinder the progress of America and those countries that are against America.

For example:

(12)We have beaten back despair and defeatism. We have saved a number of countries from losing their liberty. (Harry Truman, 1949)

(13)Standing in this same place a third of a century ago, Franklin Delano Roosevelt addressed a Nation ravaged by depression and gripped in fear. (Richard Nixon, 1969)

(14)These United States are confronted with an economic affliction of great proportions. (Ronald Reagan, 1981)

(15)We suffer from the longest and one of the worst sustained inflations in our national history. It distorts our economic decisions, penalizes thrift, and crushes the struggling young and the fixed-income elderly alike. It threatens to shatter the lives of millions of our people. (Ronald Reagan,1981)

(16)There is crime to be conquered, the rough crime of the streets. (George H.Bush, 1989)

(17)We will stand mighty for peace and freedom, and maintain a strong defense against terror and destruction. (Bill Clinton, 1997)

In the above examples, the enemies are terror, destruction, crime, inflation, depression, despair and defeatism. These enemies are powerful and will not retreat themselves. What kind of attitude should be held? To escape or surrender is definitely not allowed. The enemies are powerful but not fearful. Just as Franklin D Roosevelt said in his first inaugural address in 1933 when confronted with the Great Depression, "the only thing we have to fear is fear itself". It is the task of the people to conquer the enemies. Surrender or escape is not allowed.

\section{Building Metaphor}

Building which is common in people's life is a common source domain. A building has a base, structure, stanchion, bricks, etc. From the data two conceptual metaphors can be abstracted, namely, SOCIETY IS A BUILDING and WORTHWHILE ACTIVITY IS BUILDING.

\section{SOCIETY IS A BUILDING}

A society shares many similarities with a building. A society which is composed of people also has foundations and 
structures. In political speeches the nation, society, and its systems are usually the target domains. In building metaphor the American people are the builders and the social system is the building. In order to build and protect an edifice, efforts are needed from everyone. The political system is the base of the edifice which can not be shaken. Otherwise, the whole building will collapse. That is the most dangerous thing for a country. The following are some examples:

(18) Our whole system of self-government will crumble either if officials elect what laws they will enforce or citizens elect what laws they will support.(Herbert Hoover,1929)

(19) Thrones have toppled and their vast empires have disappeared. (Dwight D.Eisenhower, 1953)

(20) Let us remember that America was built not by government, but by people - not by welfare, but by work — not by shirking responsibility, but by seeking responsibility. (Richard Nixon, 1969)

(21) Let us resolve that we the people will build an American opportunity society... (Ronald Reagan, 1985)

(22) Communism's collapse has called forth old animosities and new dangers. (George W.Bush, 2001)

In the examples (18), (19) and (22) the social system-capitalism, thrones, and communism are conceptualized as buildings. Once they collapse, the whole country will disappear. Examples (20) and (21) emphasize that the building needs everyone to make effort to add a brick. Building metaphor is a typical example of reification.

\section{Family Metaphor}

Family metaphor is used widely in political speeches which can unite the people to a great extent. In this metaphor the government is the strict father and citizens are children.

(23)To renew America, we must be bold. We must do what no generation has had to do before. We must invest more in our own people, in their jobs, in their future, and at the same time cut our massive debt. And we must do so in a world in which we must compete for every opportunity.(Bill Clinton,1993)

(24)Each and every one of us, in our own way, must assume personal responsibility--not only for ourselves and our families, but for our neighbors and our nation. Our greatest responsibility is to embrace a new spirit of community for a new century. For any one of us to succeed, we must succeed as one America. (Bill Clinton, 1997)

Example (23)is a warning of the dangers of the outside world. In (24) the father is teaching his children what is wrong and should not be done.

The strict father provides nurturance and expresses his devotion to his family by supporting and protecting them, and also by setting and enforcing strict moral bounds and by inculcating self-discipline and self-reliance through hard work. For the strict father, strictness is a form of nurturance and love--tough love. The strict father is restrained in showing affection and emotion overtly, and prefers the appearance of strength and calm. He regards charity as an expression of compassion for those less fortunate and as an expression of gratitude for his own good fortune.

\section{E. Natural Environment Metaphor}

For the convenience of analysis, natural environment is divided into two subcategories-weather conditions and geographical features. These two source domains are less common than others; however, they are still important.

Weather condition is a conventional source domain for conveying abstract concepts of changes. This metaphor is related to a conceptual metaphor CIRCUMSTANCES ARE WEATHER. (Grady,1997, p.109) The knowledge that wind brings about a change in the weather provides a useful metaphorical representation of the cause of the change of social conditions.

Usually metaphors associated with changing conditions are more common than those associated with stable ones. So here the conceptual metaphor SOCIAL CONDITION IS WEATHER is proposed. While sunshine and breeze indicate a favorable social condition, storm and tempest imply an unpleasant condition. The more intense the weather condition is, the more intense the change is implied. Such uses are based on source knowledge of the destructive potential of the weather which is so common in our life. Weather metaphors evoke either a positive or a negative evaluation.

Usually this metaphor combines with journey metaphor as the weather condition usually affects the travel of a person. Though good weather is favored, bad weather cannot be avoided. What people should believe is that after the tempest the beautiful rainbow will be seen. People will enjoy happiness after undergoing hardships.

(25)For a new breeze is blowing, and a world refreshed by freedom seems reborn. (George W.Bush, 2001)

(26)There are times when the future seems thick as a fog; you sit and wait, hoping the mists will lift and reveal the right path. (George H.Bush, 1989)

(27)...we rode through the storm with heart and hand. (Ronald Reagan, 1985)

(28)Since this century's beginning, a time of tempest has seemed to come upon the continents of the earth. (Dwight Eisenhower, 1953)

Social conditions are closely related to the geographical features as well-SOCIAL CONDITIONS ARE GEOGRAPHICAL FEATURES. This metaphor highlights a particular aspect of a physical geographical feature which is either horizontal or vertical. When the vertical feature is involved it is related to the conceptual metaphor UP IS GOOD.

This honor now beckons America - the chance to help lead the world at last out of the valley of turmoil, and onto that high ground of peace that man has dreamed of since the dawn of civilization. (Richard Nixon, 1969)

\section{SUMMARY}


The American presidential inaugural address is an important political discourse. In the speech the new president will take advantage of this chance to make his fundamental political principles and policies public. It makes the public be clear about the political views and stands in domestic and international affairs of the new government. As a powerful weapon for politicians it plays an important role in political life. In the addresses metaphor is often used by the politicians to make their speeches more convincing.

This thesis has analyzed the political metaphors in 20 American presidential inaugural addresses by adopting the conceptual metaphor theory proposed by Lakoff and Johnson. Through the investigation, several groups of conceptual metaphors are found, namely, Journey Metaphor, Human Metaphor, War Metaphor, Building Metaphor, Family Metaphor, Light Metaphor, and Illness Metaphor, which constitute most of the metaphors in the data. In each group there are several related conceptual metaphors which together have a very important persuasive role by evoking strong emotional responses. From the analysis it is clear that the source domains are closely related to our daily life and experience which make these metaphors understandable and persuasive. Besides, different metaphors are also related to one another. Sometimes one metaphor is embedded in another one, which leads to the phenomenon that some metaphors are reflected in one single sentence.

Political metaphors have such functions as filtering, persuasion, motivation, simplification and bridge. Different metaphors highlight different aspects and thus have different functions. Metaphors are deeply rooted in people's experience and the American culture. The understanding and explanation of metaphors are closely related to the historical, social and cultural knowledge of America, which is familiar to the American people. Therefore, it is not difficult to appeal to the emotions of the Americans so as to have a better understanding of the policies of the politicians.

Metaphor analysis is a good way of revealing the underlying ideologies, attitudes and beliefs and therefore turns out to be a vital means of understanding more about the complex relationships between language, thought and culture.

\section{REFERENCES}

[1] Andrews, J.R. (1991). A Choice of Worlds-the Practice and criticism of Public Discourse. New York and Evanston: Haiper and Row, Publishers.

[2] Clarie Kramsch. (2000). Language and Culture. Shanghai: Shanghai Foreign Language.

[3] Dagrut, M. (1987). More about the Translatability of Metaphor. Babel, 2,767-83.

[4] Edelman, M. (1977). Political Language: Words that succeed and policies that fail. New York: Academic Press.

[5] F. Ungerer and H. J. Schmid. (2001). An Introduction to Cognitive Linguistics. Beijing: Foreign Language Teaching and Research Press.

[6] Goatly, A. (1997). The Language of Metaphor. London and New York: Routledge.

[7] Goodall, H. L. Jr. (1983). The Nature of Analogic Discourse. Quarterly Journal of Speech, 69, 171-179.

[8] Goodman, N. (1981). Metaphor as moonlighting. Chicago: Chicago University Press.

[9] Hunston,S.\&G.Thompson. (2000).Evaluation in Text. Oxford: Oxford University Press.

[10] Katula, Richard A. (2001). Principles and Patterns of Public Speaking. Belmont, California: Wadsworth Publishing Company.

[11] Kiewe, M. (1998). The Crisis Tool in American Political Discourse. In O. Feldman \& Christ' l De Land sheer (eds.), Politically Speaking - a Worldwide Examination of Language Used in the Public Sphere. London: Praeger Publishers.

[12] Kavecses, Z.\&P.Szabó. (1996). Idioms:A View from Cognitive Semantics. Applied Linguistics, 3, 326-51.

[13] Lakoff, G.and M. Johnson. (1980). Metaphors We Live By. Chicago: Chicago University Press.

[14] Landtsheer,C.D.(1998). Introduction to the Study of Political Discourse. In O. Feldman \& C.D. Landtsheer (eds.). Politically Speaking: A Worldwide Examination of Language Used in the Public Spheer. London: Prager Publishers.

[15] Lasswell, H.D. \& N. Leites. (1949). Language of Politics: Studies in Quantitative Semantics. New York: George W. Stewart.

[16] Leezenberg, M. (2001). Contexts of Metaphor. Amsterdam: University of Amsterdam.

[17] Mio, Jeffery and Albert N. Katz. (1996). Metaphor: Implications and Applications. New Jersey: Lawrence Erlbaum Associations Publishers.

[18] Nimmo, D. R. \& Coombs, J.E. (1987). Mediated Political Realities. New York: Longman.

[19] Newmark,R.(1980). The Translation of Metaphor. Babel, 2, 93-100.

[20] Orwell, George. (1946). Politics and the English Language. Harmondsworth: Penguin.

[21] Oxford Advanced Learner's English-Chinese Dictionary (the $6^{\text {th }}$ edition) (2005).Beijing: The Commercial Press \& Oxford University Press.

[22] Richards, I.A. (1936). The Philosophy of Rhetoric. Oxford: Oxford University Press.

[23] Steen, Gerard. (2002). Identifying Metaphor in Language: A Cognitive Approach. Style.3, 386-407.

[24] Steen, Gerard. (1999). From Linguistic to Conceptual Metaphor in Five Steps. In Raymond W. Gibbs, JR \& Gerard J. Steen eds. Metaphor in Cognitive Linguistics. Amsterdam: John Benjamins publishing Company.

[25] Swales. (1990). Genre Analysis English - in Academic and Research Settings. Cambridge: Cambridge University Press.

Jiao Xue was born in Yangzhou, China in 1986. She received her M.A degree in foreign linguistics and applied linguistics from Jiangsu University of Science and Technology, China in 2011.

She is currently a tutor in English Department, Zhenjiang Watercraft College, Zhenjiang, China. Her research interests include second language acquisition and intercultural communication. 
Zan Mao was born in Zhenjiang, China in 1985. She received her B.A. degree in Foreign Linguistics from Shanghai Normal University, China in 2007.

She is currently an assistant in English Department, Zhenjiang Watercraft College, Zhenjiang, China. Her research interests include Second Language Acquisition and Foreign Language Teaching.

Na Li was born in Zhenjiang, China in 1982. She received her B.A. degree in Linguistics from Guilin Industrial College, China in 2006.

She has been teaching English for 4 years in Watercraft College, Zhenjiang. Her research interests include English Linguistic and Literature Translation. 